\title{
Protection of sperm DNA against oxidative stress in vivo by accessory sex gland secretions in male hamsters
}

\author{
H. Chen ${ }^{1}$, M. P. L. Cheung ${ }^{1}$, P. H. Chow ${ }^{2}$, \\ A. L. M. Cheung ${ }^{1}$, W. Liu ${ }^{1}$ and W. S. $\mathrm{O}^{1 *}$ \\ ${ }^{1}$ Department of Anatomy, Faculty of Medicine, The University of Hong Kong, \\ 21 Sassoon Road, Hong Kong, PR China; and ${ }^{2}$ The Chinese University of Hong Kong, \\ Hong Kong SAR, PR China
}

Reactive oxygen species scavengers present in male accessory sex gland secretions might afford antioxidant protection to sperm DNA. This study was conducted to determine whether accessory sex gland secretions protect the genome and function of spermatozoa against oxidative damage in the uterus. Male golden hamsters were divided into four experimental groups: (i) all accessory sex glands removed; (ii) ampullary glands removed; (iii) ventral prostate gland removed and (iv) sham-operated controls. Ejaculated spermatozoa recovered from uteri 15-30 min after mating with experimental males and caput and cauda epididymal spermatozoa obtained from intact males were incubated in 0-20 mmol NADPH $\mathrm{l}^{-1}$ for $2 \mathrm{~h}$. These spermatozoa and untreated uterine spermatozoa were processed for two types of comet assay (single cell gel electrophoresis): alkaline comet assay $(\mathrm{pH}>13)$ which revealed single-strand DNA breakage and neutral comet assay ( $\mathrm{pH}$ 9) which revealed double-strand DNA breakage. In comparison with the sham-operated controls, spermatozoa that had not been exposed to accessory sex gland secretions had a higher incidence and more extensive single-strand DNA damage with increasing concentrations of NADPH. Spermatozoa from hamsters without ampullary glands and from hamsters without the ventral prostate glands were similar to those of the control group. After incubation with NADPH, the capacity of spermatozoa from hamsters without accessory glands and from sham-operated controls to fuse with oocytes in vitro was reduced. However, only hamsters without accessory glands showed a negative correlation between single-strand DNA damage and sperm-oocyte fusion. Cauda epididymal spermatozoa were less susceptible to NADPH treatment compared with caput epididymal spermatozoa. The results of the present study showed that male accessory sex gland secretions can preserve the integrity of the sperm genome.

\section{Introduction}

In golden hamsters, the main male accessory sex glands include the ampullary glands, ventral prostate gland, dorsolateral prostate glands, coagulating glands and seminal vesicles. The secretions of these glands contain antioxidant enzymes, such as superoxide dismutase, catalase and glutathione peroxidase, and free radical scavengers, such as vitamins $C$ and $E$, hypotaurine, taurine, uric acid and albumin. These small molecular scavengers are thought to contribute significantly to antioxidant protection of spermatozoa (van Overveld et al., 2000). In addition, albumin present in human seminal plasma protects spermatozoa against peroxidative damage by absorbing lipid peroxides from the plasma membrane of spermatozoa (Twigg et al., 1998).

Reactive oxygen species (ROS) are free radicals, such as superoxide anions, hydroxyl radicals and $\mathrm{H}_{2} \mathrm{O}_{2}$. ROS may influence the structural integrity and function of

*Correspondence

Email: owaisum@hkucc.hku.hk spermatozoa, such as motility, capacitation and spermoocyte fusion (Jones and Mann, 1976; Aitken, 1995; Griveau et al., 1995; de Lamirande and Gagnon, 1995a,b). A fine balance to maintain an optimal amount of ROS is affected by ROS generated during sperm maturation in the epididymis and antioxidant factors in secretions of the male reproductive system. Spermatozoa experience adverse oxidative stress once this balance is lost. ROS have been shown to reduce male fertility (Iwasaki and Gagnon, 1992), cause peroxidative damage to the sperm plasma membrane (Hughes et al., 1996) and induce both DNA strand breakages and oxidative base damage in human spermatozoa (Kodama et al., 1997). In addition, a decrease in the total antioxidant capacity of seminal plasma has been correlated with a reduction in sperm quality factors, such as concentration, motility and morphology (Lewis et al., 1994; Palan and Naz, 1996; Smith et al., 1996; Sharma et al., 1999).

It has been shown that removal of all or some of the accessory sex glands in the golden hamster reduces male fertility with respect to a decrease in preimplantation cleavage, implantation rate and an increase in post-implantation abnormality or loss of embryos (O et al., 1988; Jiang et al., 
2001; Chan et al., 2001). Oocyte activation, sperm decondensation and DNA synthesis during the first cell cycle were also adversely affected (Ying et al., 1998; 1999a,b). We proposed that damage to sperm genomic integrity might be one of the causes.

Comet assay, also known as single cell gel electrophoresis, has been applied to detect the integrity of sperm DNA. This is a rapid, simple, visual and sensitive technique for measuring alkali labile sites and DNA strand breakages in individual mammalian cells (Ostling and Johanson, 1984; Singh et al., 1988; Olive et al., 1990). The introduction of an alkaline $(\mathrm{pH}>13)$ condition to unwind, denature and separate by electrophoresis makes the relationship of single-strand DNA (ssDNA) breakage more obvious. During electrophoresis, the fragmented DNA migrates to form a comet-like image. The 'head' consists of intact DNA, whereas the 'tail' contains fragmented DNA. Furthermore, the assay can detect different types of DNA damage according to the $\mathrm{pH}$ of the buffers used. In highly alkaline buffer $(\mathrm{pH}>13)$, the assay can expose nicks, apurine/ apyrimidine sites and other alkaline labile sites, and detect the ssDNA damage. In neutral buffer $(\mathrm{pH} 9)$, the assay can be applied to analyse double-strand DNA (dsDNA) breaks.

The aim of the present study was to apply the comet assay and sperm-oocyte fusion test to assess the susceptibility of sperm DNA to ROS damage and functional integrity in relation to bilateral ablation of male accessory sex glands in the golden hamster.

\section{Materials and Methods}

All chemicals were purchased from Sigma Chemical Co. (St Louis, MO) unless otherwise stated. Tyrode's albumin lactate pyruvate (TALP, pH 7.4 ( $\mathrm{pH} 7.7$ before gassing), 285-290 mOsm) medium was prepared with Milli-Q water and composed of $114.0 \mathrm{mmol} \mathrm{NaCl} \mathrm{I}^{-1}$ (BDH, Poole), $3.2 \mathrm{mmol} \mathrm{KCl} \mathrm{I-1}, 2.0 \mathrm{mmol} \mathrm{CaCl}_{2} \cdot 2 \mathrm{H}_{2} \mathrm{O} \mathrm{I}^{-1}, 0.4 \mathrm{mmol}$ $\mathrm{NaH}_{2} \mathrm{PO}_{4} \cdot \mathrm{H}_{2} \mathrm{O} \mathrm{I}^{-1}, 5.0 \mathrm{mmol}$ D-glucose $\mathrm{I}^{-1}$ (E. Merck, Darmstadt), $0.5 \mathrm{mmol} \mathrm{MgCl}_{2} \cdot 6 \mathrm{H}_{2} \mathrm{O} \quad \mathrm{I}^{-1}, \quad 25.0 \mathrm{mmol}$ $\mathrm{NaHCO}_{3} \mathrm{I}^{-1}, 10.0 \mathrm{mmol}$ sodium lactate $\mathrm{I}^{-1}, 0.1 \mathrm{mmol}$ sodium pyrúvate $\mathrm{I}^{-1}, 0.1 \mathrm{mmol}$ sodium penicillin $\mathrm{G} \mathrm{I}^{-1}$, $0.01 \mathrm{mg}$ phenol red $\mathrm{ml}^{-1}$ and $3.0 \mathrm{mg} \mathrm{BSA} \mathrm{ml}^{-1}$. Modified TALP (mTALP) medium for capacitation contained $0.5 \mathrm{mmol}$ taurine $\mathrm{I}^{-1}, 0.05 \mathrm{mmol}$ adrenaline $\mathrm{I}^{-1}$ (CALBIOCHEM, San

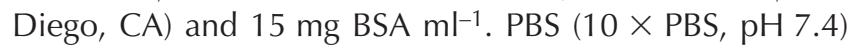
composed of $80.1 \mathrm{~g} \mathrm{NaCl}, 2.0 \mathrm{~g} \mathrm{KCl}, 11.5 \mathrm{~g} \mathrm{Na}_{2} \mathrm{HPO}_{4}$ (Fisher, Fairlawn, NJ) and $2.0 \mathrm{~g} \mathrm{KH}_{2} \mathrm{PO}_{4}$ (WAKO, Osaka) in 1 I Milli-Q water, was diluted 10-fold just before use.

\section{Animal model}

Animals were maintained and handled in compliance with a protocol approved by the Committee on the Use of Live Animals for Teaching and Research of The University of Hong Kong. Randomly bred Syrian hamsters (Mesocricetus auratus) were supplied by and housed in the Laboratory Animal Unit (Faculty of Medicine, The University of Hong Kong) under a $14 \mathrm{~h}$ light:10 h dark photoperiod, lights on at
11:00-01:00 h, at $22^{\circ} \mathrm{C}$. Food and tap water were available ad libitum. Vaginal secretions of 6-8-week-old female hamsters were checked daily for at least two normal consecutive oestrous cycles before mating.

The main male accessory sex glands were surgically ablated from 6-8-week-old male hamsters as described by Chow et al (1986) to give the following four groups: (i) bilateral excision of ampullary glands (AGX, $n=8$ ); (ii) excision of ventral prostate (VPX, $n=8$ ); (iii) bilateral excision of the ampullary glands, ventral prostate, dorsolateral prostates, coagulating glands and seminal vesicles (TX, $n=10)$ and (iv) sham-operated control hamsters $(\mathrm{SH}, n=8)$. The animals were allowed to recuperate for 1 month and the success of surgery was confirmed post-mortem.

\section{Preparation of spermatozoa}

Collection of epididymal spermatozoa. Eight- to twelveweek-old male hamsters of proven fertility were killed with an overdose of sodium pentobarbitone injected i.p. (Boehringer Ingelheim, Artarmon). The caput and cauda epididymides were removed. After clearing blood and connective tissue, small incisions were made to release spermatozoa. The spermatozoa were washed twice in TALP medium and centrifuged at $300 \mathrm{~g}$ for $10 \mathrm{~min}$ to form a pellet.

Collection of uterine spermatozoa. Each normal cyclic female hamster was mated with one operated male for 15 min on the day of oestrus and killed with an overdose of sodium pentobarbitone within $30 \mathrm{~min}$ after mating. The uterine horns were removed and cleaned of blood and connective tissue. Spermatozoa collected from the uteri of two females by flushing with TALP medium were pooled together, washed and centrifuged twice at $300 \mathrm{~g}$ for $10 \mathrm{~min}$.

\section{Treatment of spermatozoa with $\beta-N A D P H$}

Uterine spermatozoa ejaculated by males from all four experimental groups were subjected to comet assay. These spermatozoa, together with caput and cauda epididymal spermatozoa from intact males were incubated at a final concentration of $1 \times 10^{6}$ cells $\mathrm{ml}^{-1}$ for $2 \mathrm{~h}$ in $0,1.25,2.5$, 5.0, 10.0 and $20.0 \mathrm{mmol} \mathrm{NADPH} \mathrm{I}{ }^{-1}$ at $37^{\circ} \mathrm{C}$ in $5 \% \mathrm{CO}_{2}$. After incubation, the treated spermatozoa were centrifuged twice at $300 \mathrm{~g}$ for $10 \mathrm{~min}$ to form a pellet and resuspended in fresh medium for comet assay and sperm-oocyte fusion.

\section{Sperm-oocyte fusion}

Female hamsters were killed by an overdose of sodium pentobarbitone on the day of oestrus. Oocytes were recovered from the oviducts by flushing with BSA-free TALP. Cumulus cells and zonae pellucidae were removed by incubation in $0.1 \%(\mathrm{w} / \mathrm{v})$ hyaluronidase and $0.05 \%(\mathrm{w} / \mathrm{v})$ trypsin. Oocytes were washed twice with TALP containing BSA. The zona pellucida-free oocytes were dispensed into the prepared sperm droplets (five oocytes per droplet of spermatozoa, which was repeated three times per concen- 
tration of NADPH treatment as described previously). After incubation at $37^{\circ} \mathrm{C}$ in $5 \% \mathrm{CO}_{2}$ for $6 \mathrm{~h}$, the oocytes were collected and washed free of loosely adhered spermatozoa, transferred on to silanized slides (DAKO, Glostrup), airdried overnight and fixed in $70 \%$ ethanol for $30 \mathrm{~min}$. The slides were treated with $0.1 \%(\mathrm{v} / \mathrm{v})$ Tween-20 and TritonX100 in PBS for 20 min in a humid chamber followed by three washes in PBS. The oocytes were stained with $10 \mu \mathrm{g}$ propidium iodide $\mathrm{ml}^{-1}$ (Molecular Probes, Eugene, OR) for $10 \mathrm{~min}$ and observed under an epifluorescence microscope (Zeiss) fitted with $510-560 \mathrm{~nm}$ excitation filter, $580 \mathrm{~nm}$ dichromatic mirror and $590 \mathrm{~nm}$ emission filter. The number of decondensed sperm heads per oocyte was counted.

\section{Assessment of sperm DNA damage by the comet assay}

The comet assay was adapted from Shen and Ong (2000) and was performed in the dark. Spermatozoa were resuspended in PBS at 6-8 $610^{5}$ cells $\mathrm{ml}^{-1}$. Ten microlitres of sperm suspension was mixed with $75 \mu \mathrm{l}(0.5 \%$, w/v) agarose SFR ${ }^{\mathrm{TM}}$ (Amresco, Solon, OH). After mixing thoroughly, $50 \mu$ of the sperm suspension was pipetted on to a CometSlide (Trevigen, Gaithersburg, MD) and allowed to gel. The slides were submersed carefully in cold lysis buffer $\left(2.5 \mathrm{~mol} \mathrm{NaCl} \mathrm{I-1}, 100.0 \mathrm{mmol}\right.$ EDTA ${ }^{-1}, 10.0 \mathrm{mmol}$ Tris- $\mathrm{HCl} \mathrm{I}{ }^{-1}, 10 \%(\mathrm{v} / \mathrm{v})$ dimethyl sulphoxide and $1 \%(\mathrm{v} / \mathrm{v})$ Triton-X100, $\mathrm{pH} 10)$ for $1 \mathrm{~h}$ at $4{ }^{\circ} \mathrm{C}$. For the neutral comet assay, the slides were pretreated with buffer $(2.5 \mathrm{~mol} \mathrm{NaCl}$

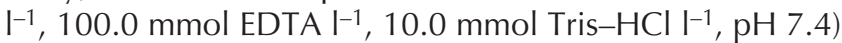
containing $10 \mu \mathrm{g}$ RNase $\mathrm{ml}^{-1}$ (Amresco) and incubated for $2 \mathrm{~h}$ at $37^{\circ} \mathrm{C}$. The slides were then transferred to another buffer (2.5 mol $\mathrm{NaCl} \mathrm{I}^{-1}, 100.0 \mathrm{mmol}$ EDTA I-1, 10.0 mmol Tris- $\mathrm{HCl} \mathrm{I}^{-1}$, $\mathrm{pH}$ 7.4) containing $10 \mu \mathrm{g}$ DNasefree proteinase $\mathrm{K} \mathrm{m}^{-1}$ (Amresco) and incubated at $37^{\circ} \mathrm{C}$ overnight. For the alkaline comet assay, slides were handled in the same way as for the neutral comet assay, without pretreatment.

After enzyme treatment, the slides were transferred into the electrophoresis chamber (Hoefer Pharmacia Biotech, San Francisco, CA) filled with neutral buffer $(300 \mathrm{mmol}$ sodium acetate $\mathrm{I}^{-1}$ and $100 \mathrm{mmol}$ Tris- $\mathrm{HCl} \mathrm{I-1}, \mathrm{pH}$ 9) or alkaline buffer (300 mmol $\mathrm{NaOH} \mathrm{I}^{-1}$ (E. Merck), $1 \mathrm{mmol}$ EDTA I-1 $0.2 \%(\mathrm{v} / \mathrm{v})$ dimethyl sulphoxide and $0.1 \%(\mathrm{w} / \mathrm{v}) 8^{-}$ hydroxyquinoline, $\mathrm{pH}>13$ ). The slides were left side by side in the respective buffer to allow unwinding of the DNA for $20 \mathrm{~min}$, before electrophoresis at $0.96 \mathrm{~V} \mathrm{~cm}^{-1}, 100 \mathrm{~mA}$ (for neutral comet assay) or $250 \mathrm{~mA}$ (for alkaline comet assay) for $20 \mathrm{~min}$ at room temperature. After electrophoresis, the slides were neutralized in 0.4 mol Tris- $-\mathrm{HCl} \mathrm{I}^{-1}(\mathrm{pH} 7.4)$ for $15 \mathrm{~min}$, fixed in $100 \%$ ethanol for $15 \mathrm{~min}$ and then air-dried. The dried slides were treated in $10 \mathrm{mmol} \mathrm{NaH}_{2} \mathrm{PO}_{4} \mathrm{I}^{-1}$ and $5 \%$ $(\mathrm{w} / \mathrm{v})$ sucrose for $10 \mathrm{~min}$ and finally stained with $0.25 \mathrm{mmol}$ YOYO $^{\circledR}-1 \mathrm{I}^{-1}$ (Molecular Probes) in $5 \%(\mathrm{v} / \mathrm{v})$ dimethyl sulphoxide and 5\% (w/v) sucrose for $10 \mathrm{~min}$.

CometSlides were viewed at $\times 250$ under a Zeiss fluorescence microscope. The incidence of spermatozoa with a comet was scored from each circle of the CometSlide (two circles) and expressed as the number of comets per 10000 spermatozoa. The comets were captured with a cooled CCD camera (KX Series Imaging System, Apogee Instruments Inc, Tucson, AZ) connected to the Zeiss fluorescent microscope and the images were evaluated for tail moment from 50 randomly selected comets using a Euclid Comet Analysis Software (Euclid Analysis, St Louis, MO). DNA damage was quantified as tail moment, which was defined as the fraction of DNA in the tail multiplied by the distance of fragmented DNA from the centre of the head (Olive et al., 1990).

\section{Statistical analysis}

All results are presented as mean \pm SEM. The incidence of DNA damage and sperm function (expressed as the number of decondensed spermatozoa per oocyte) was arcsine and square root transformed, respectively, before statistical analyses (Prism software version 3.0, GraphPad, San Diego, CA). All results, including transformed or original data were analysed by one-way ANOVA followed by Dunnett's post-test. Two-way ANOVA followed by Bonferroni post-test was also applied to analyse the response of caput and cauda epididymal spermatozoa as well as uterine spermatozoa to NADPH incubation and sperm-oocyte fusion test. The distribution of comet patterns in relation to increasing amounts of NADPH in caput spermatozoa was analysed by linear regression. Moreover, the relationship between the observed amounts of DNA damage and sperm-oocyte fusion was analysed by correlation. $P<0.05$ was considered significant. Each experiment was repeated at least five times.

\section{Results}

\section{Effects of deletion of male accessory sex glands on} uterine sperm DNA damage

The incidence of DNA damage in uterine spermatozoa is shown (Fig. 1a). The incidence of both ssDNA and dsDNA breakage was significantly different among the four experimental groups (alkaline assay: $F=5.935, P<0.05$; neutral assay: $F=9.745, P<0.05)$. Spermatozoa from the TX group showed a significant increase in the incidence of ssDNA and dsDNA breakage compared with the $\mathrm{SH}$ group $(P<0.05)$. Moreover, the total incidence of spermatozoa from the TX group with DNA damage (ssDNA and dsDNA damage) was higher than that of spermatozoa from the $\mathrm{SH}$ group ( $\mathrm{TX}=2.58 \%$; $\mathrm{SH}=0.69 \%$ ), whereas spermatozoa from both AGX and VPX groups did not show any significant difference compared with spermatozoa from the $\mathrm{SH}$ group. The extent of DNA damage (tail moment) in uterine spermatozoa is shown (Fig. 1b). A significant difference in alkaline comet assay was found in the experimental groups $(F=4.016, \quad P<0.05)$. Spermatozoa from the TX group showed a greater extent of ssDNA damage compared with control spermatozoa $(P<0.05)$. However, spermatozoa from both AGX and VPX groups were not different from those of the control group. 


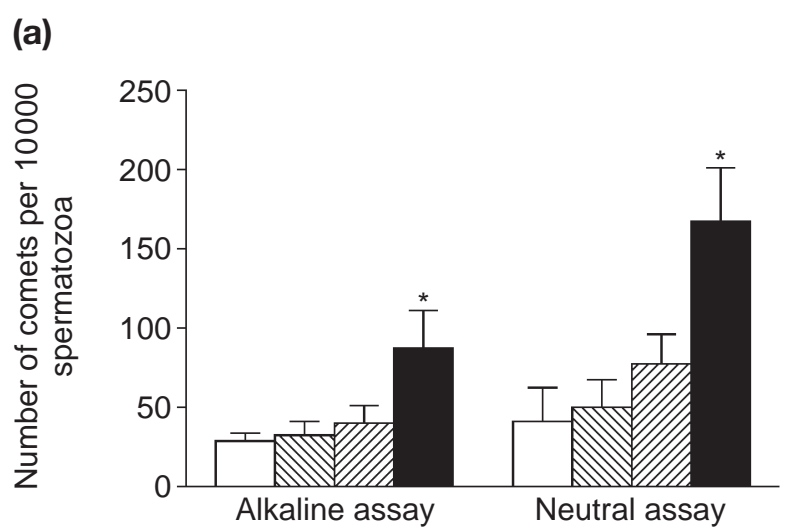

(b)

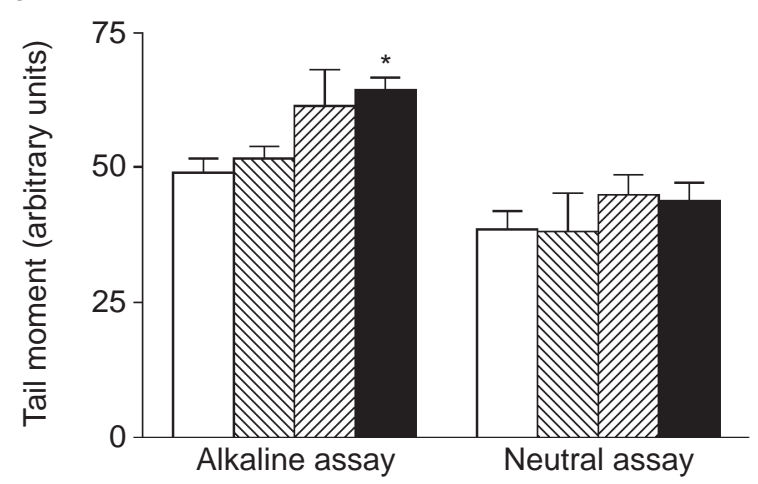

Fig. 1. The (a) incidence and (b) extent of DNA damage in spermatozoa of the male golden hamster after the removal of the accessory sex glands (TX, $\mathbf{\square})$, the removal of the ampullary glands $(A G X, \mathbb{N})$, the removal of the ventral prostate (VPX, $\square$ ) and in sham-operated controls ( $\mathrm{SH}, \square)$. Asterisks indicate significant increases in the incidence of (a) single-strand DNA damage (alkaline assay) and double-strand DNA damage (neutral assay), and the extent of (b) single-strand DNA damage (alkaline assay) compared with sham-operated controls $(P<0.05$; one-way ANOVA followed by Dunnett's post-test).

\section{Susceptibility of epididymal and uterine spermatozoa to} induced ROS damage

Spermatozoa from the caput and cauda epididymides and uterine spermatozoa ejaculated by males from the control and experimental groups were incubated with $\mathrm{NADPH}$ followed by comet assay to assess the response of epididymal spermatozoa to ROS at different maturation stages and the protective effects of male accessory sex gland secretions against the induced ROS.

\section{Epididymal spermatozoa from intact males of proven fertility}

After NADPH incubation, a significantly higher incidence of ssDNA damage was found in spermatozoa from the caput compared with the cauda epididymidis $(F=227.50$,
$P<0.001$ ) (Table 1). Spermatozoa from the caput epididymidis showed no significant change in the incidence of ssDNA damage after incubation with various concentrations of NADPH. The comet from caput epididymal spermatozoa was categorized into three patterns (Fig. 2). Pattern 1: comets only with comet head (intact DNA) but no tail (fragmented DNA); pattern 2: comets with various head and tail sizes; and pattern 3: no comet head (intact DNA). Even though NADPH incubation did not affect the incidence of ssDNA damage in caput epididymal spermatozoa, a higher percentage of pattern 3 (ssDNA breakage) was evident at higher $\mathrm{NADPH}$ concentration $\left(R^{2}=0.4220\right.$, $P<0.001)$.

\section{Uterine spermatozoa from males with all or some of the accessory sex glands removed}

The incidence of ssDNA breakage in uterine spermatozoa from experimental groups incubated with increasing concentrations of NADPH is shown (Fig. 3a). There was a significant dose-dependent increase in the incidence of ssDNA damage in spermatozoa from the experimental groups $(F=49.2571, P<0.001)$; however, data on spermatozoa from the TX group showed significance only when compared with the control group $(P<0.001)$. Spermatozoa from both the AGX and VPX groups showed a significant increase in the incidence of ssDNA damage when compared with the control group $(P<0.05)$, but a doseresponse mode was not observed. The extent of ssDNA damage in uterine spermatozoa from the different experimental groups in response to incubation with NADPH (Fig. $3 \mathrm{~b})$ showed a significant dose-dependent increase among the four groups $(F=12.1161, P<0.001)$. Spermatozoa from the TX group showed a larger dose-dependent increase compared with that from the $\mathrm{SH}$ group $(P<0.05)$. However, neither AGX nor VPX groups showed any significant difference from the $\mathrm{SH}$ group.

It was worth noting that the extent of ssDNA damage among spermatozoa from SH, AGX, VPX and TX groups were significantly different after $2 \mathrm{~h}$ of incubation without $\mathrm{NADPH}(\mathrm{SH}=48.83 \pm 2.95 ; \mathrm{AGX}=51.60 \pm 2.21 ; \mathrm{VPX}=$ $61.20 \pm 6.80 ; T X=64.25 \pm 2.29$ ), which is similar to the response of spermatozoa that were not subjected to incubation (Fig. 1b). However, after treatment with up to $10 \mathrm{mmol}$ $\mathrm{NADPH} \mathrm{I}^{-1}$, the extent of ssDNA damage in all samples was similar $(\mathrm{SH}=71.86 \pm 3.48 ; \mathrm{AGX}=69.83 \pm 3.83 ; \mathrm{VPX}=$ $66.60 \pm 6.80 ; \mathrm{TX}=76.93 \pm 3.39)$.

\section{DNA damage and sperm-oocyte fusion}

After incubation with an increasing amount of $\mathrm{NADPH}$, uterine spermatozoa recovered from $\mathrm{SH}$ and TX groups showed no difference in their ability to fuse with oocytes. However, a dose-dependent decrease in the number of decondensed spermatozoa per oocyte was noted (Fig. 4; $\left.\mathrm{SH}: R^{2}=0.6071, P<0.001 ; \mathrm{TX}: R^{2}=0.7061, P<0.001\right)$. A linear correlation was found between ssDNA damage and sperm-oocyte fusion. This result showed that the induction 
Table 1. Incidence of DNA damage in hamster caput and cauda epididymal spermatozoa after NADPH treatment

\begin{tabular}{lccr}
\hline \multirow{2}{*}{$\begin{array}{l}\text { NADPH } \\
\left(\text { mmol I }^{-1}\right)\end{array}$} & $\begin{array}{c}\text { Number of } \\
\text { animals }\end{array}$ & \multicolumn{2}{c}{ Number of comets per 10000 spermatozoa } \\
\cline { 3 - 4 } 0 & 5 & $153 \pm 25$ & Cauda epididymidis \\
\hline 1.25 & 5 & $201 \pm 35$ & $8 \pm 3$ \\
2.5 & 5 & $200 \pm 43$ & $13 \pm 3$ \\
5.0 & 5 & $191 \pm 16$ & $11 \pm 4$ \\
10.0 & 5 & $216 \pm 24$ & $10 \pm 2$ \\
20.0 & 5 & $130 \pm 10$ & $10 \pm 3$ \\
\hline
\end{tabular}

Values are mean \pm SEM.

***Significantly higher compared with cauda epididymal spermatozoa in all concentrations of NADPH $(P<0.001$; two-way ANOVA followed by Bonferroni post-test).

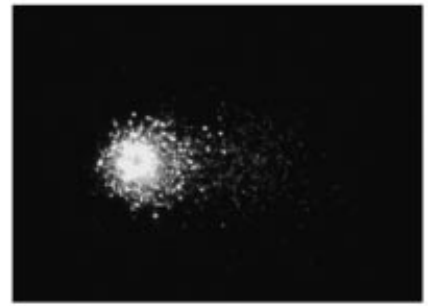

Pattern 1

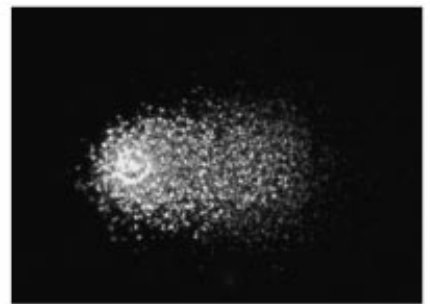

Pattern 2
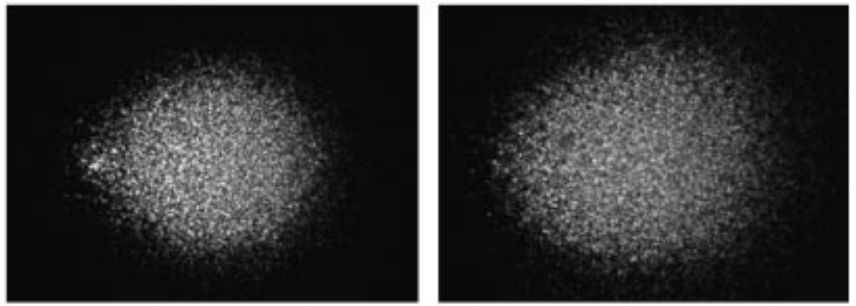

Pattern 3

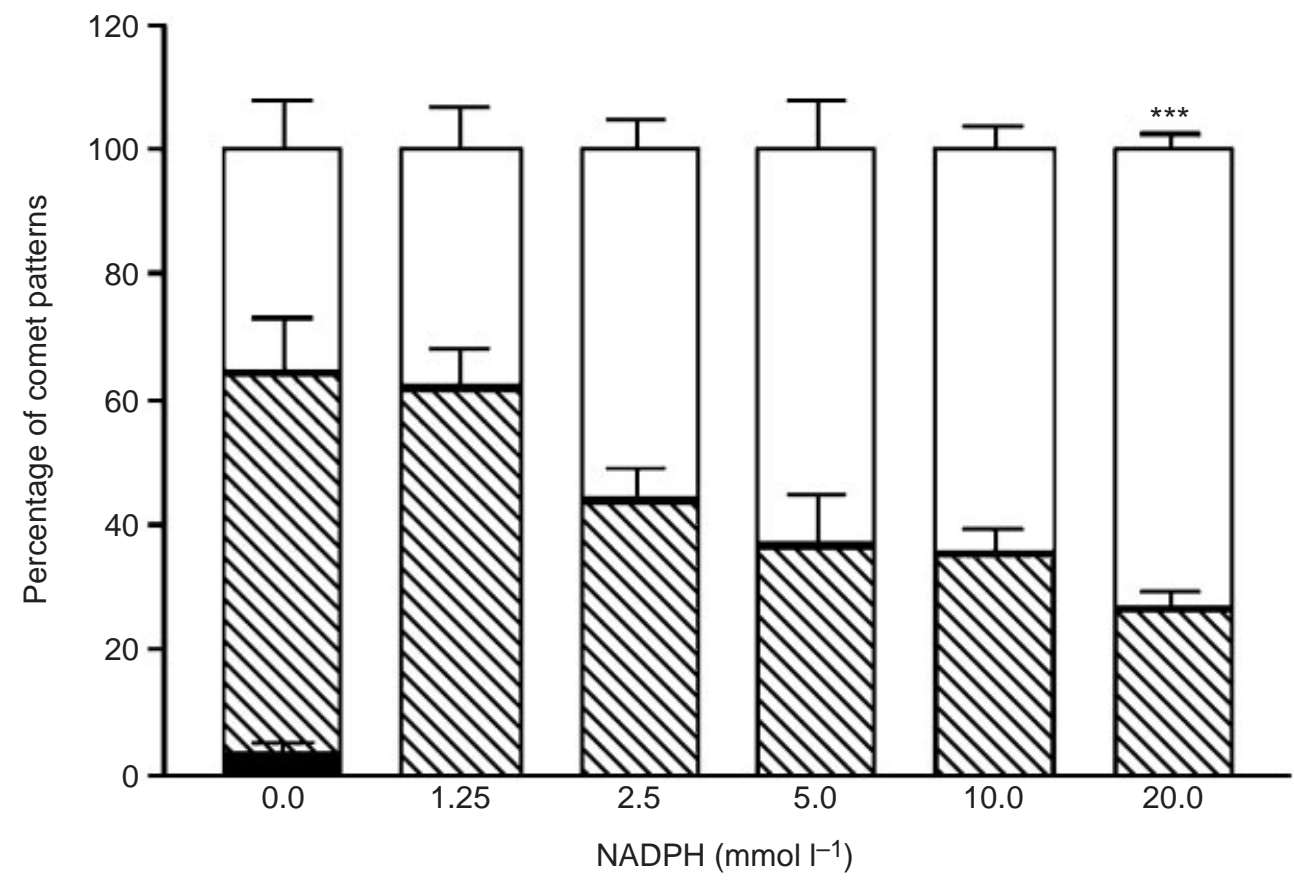

Fig. 2. Comet patterns in hamster caput epididymal spermatozoa after NADPH treatment. Asterisks indicate that caput epididymal spermatozoa showed a significantly higher percentage in comet pattern 3 after NADPH treatment $\left(R^{2}=0.4220 ; P<0.001\right)$. $\mathbf{\square}$ : pattern 1, comets only with comet head (intact DNA) but no tail (fragmented DNA); $\mathbf{\nabla}$ : pattern 2, comets with various head and tail sizes; $\square$ : pattern 3, no comet head (intact DNA).

of ssDNA damage by NADPH results in a significant negative correlation with sperm-oocyte fusion in spermatozoa from the TX group $(r=-0.9579 ; P<0.05)$. However, such a relationship was not found in the $\mathrm{SH}$ group $(r=-0.9069)$.

\section{Discussion}

The present study demonstrated that DNA damage was more extensive in spermatozoa that were not exposed to 


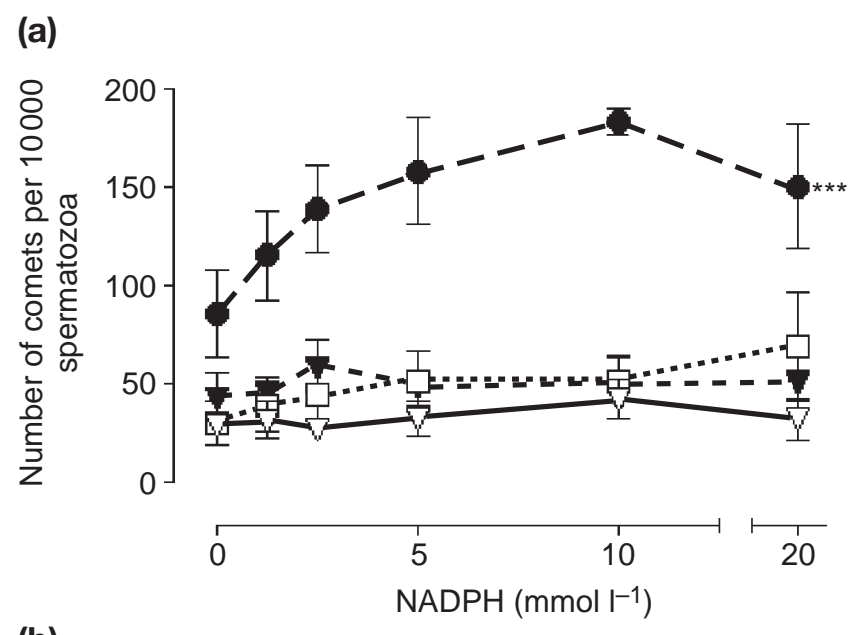

(b)

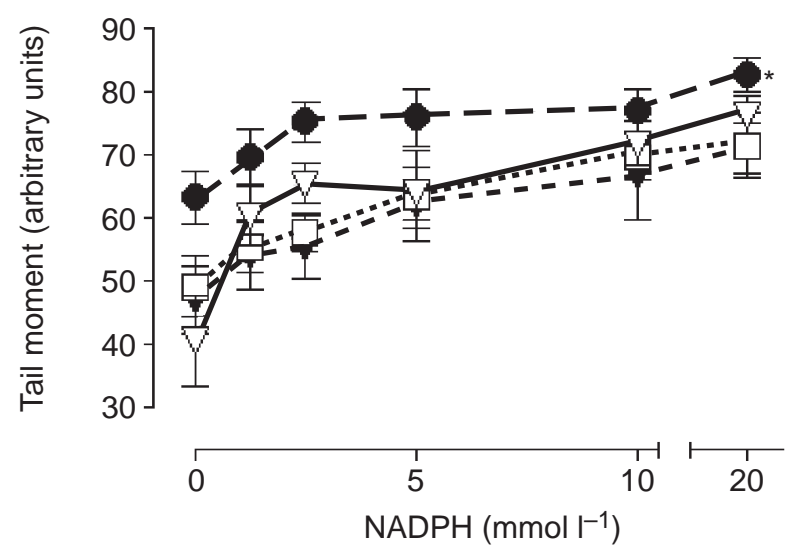

Fig. 3. The (a) incidence and (b) extent of sperm DNA damage in male golden hamsters after NADPH treatment. Spermatozoa from experimental hamsters after the removal of the male accessory sex glands $(\bullet)$ showed a significantly higher incidence and extent of single-strand DNA damage compared with spermatozoa from sham-operated control hamsters $(\nabla)$ $\left({ }^{* *} P<0.001 ; \quad * P<0.05 ; \quad\right.$ two-way ANOVA followed by Bonferroni post-test). However, spermatozoa from experimental hamsters after the removal of ampullary glands $(\square)$ and after the removal of the ventral prostate $(\boldsymbol{\nabla})$ were not different from spermatozoa from sham-operated control hamsters $(\nabla)$.

male accessory sex gland secretions. Mature epididymal spermatozoa were less susceptible to NADPH treatment, and male accessory sex gland secretions afford protection to uterine sperm from DNA breakage after NADPH treatment, indicating that male accessory sex gland secretions might have a role in preserving sperm genomic integrity in the female genital tract.

During sperm maturation, chromatin is packed through increasing disulfide bond formation upon oxidation of protamine thiols. The thiol-disulfide status is important in DNA stability (Kosower et al., 1992). DNA-associated protamines deficient in disulfide could lead to ssDNA damage. In the present study, after incubation for $2 \mathrm{~h}$ without $\mathrm{NADPH}$, spermatozoa from the caput epididymidis

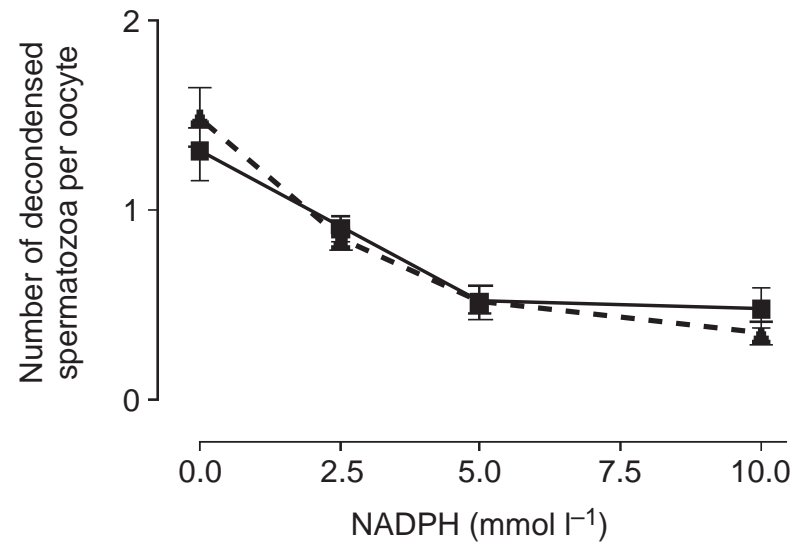

Fig. 4. The sperm-oocyte fusion test in uterine spermatozoa from male golden hamsters after NADPH treatment. No significant difference was found between sham-operated control hamsters $(\mathrm{SH}, \boldsymbol{\square})$ and experimental hamsters with all male accessory sex glands removed (TX, $\mathbf{\Delta})(P>0.05)$. A dose-dependent decrease in the number of decondensed spermatozoa per oocyte was observed (SH: $R^{2}=0.6071 ; P<0.001 ;$ TX: $\left.R^{2}=0.7061 ; P<0.001\right)$.

appeared to be more vulnerable to denaturation and suffer more extensive ssDNA damage than did spermatozoa from the cauda epididymidis, which might be due to a difference in chromatin condensation (Weissenberg et al., 1994). However, changes in the redox status of mammalian spermatozoa seem to have great impact on the completion of chromatin compaction. Fisher and Aitken (1997) reported that when induced by NADPH, spermatozoa from the caput epididymidis have a higher spontaneous capacity for superoxide anion production than do spermatozoa from other regions of the epididymis. This higher capacity appears to be mediated by a membrane-bound NADPH oxidase, which may generate hydrogen peroxide acceptors for phospholipid hydroperoxide glutathione peroxidase $(\mathrm{PH}-\mathrm{GPx}$ or GPx4) during induction of sperm chromatin condensation (ROS-PH-GPx system) (Aitken and Vernet, 1998). Too little ROS may lead to a failure of chromatin condensation and an increase in susceptibility to DNA damage (Bianchi et al., 1993). In contrast, too much ROS overwhelms intracellular GPx and PH-GPx leading to oxidative stress and DNA damage (Hughes et al., 1996). The present study also observed a dose-dependent increase in the extent of ssDNA damage in spermatozoa from the caput epididymidis after $\mathrm{NADPH}$ incubation, but this dose-dependent effect is not evident in the cauda epididymidis. It is possible that this finding resulted from poorly packaged chromatin (rich in thiol) and a high capacity of superoxide anion production by NADPH oxidase in the plasma membrane of caput epididymal spermatozoa. Thus, the results of the present study indicate that the immature caput epididymal spermatozoa are more vulnerable to $\mathrm{NADPH}$-induced ssDNA damage than are mature spermatozoa from the cauda epididymidis.

DNA damage of human ejaculated spermatozoa might 
arise from three sources: underprotamination during spermiogenesis, abortive apoptosis during spermatogenesis (Sakkas et al., 1999) and oxidative stress (Alvarez et al., 1987; Aitken and Fisher, 1994). The main cause of oxidative stress may be a high rate of ROS generated in association with the retention of excess residual cytoplasm in the mid-piece of spermatozoa and antioxidant depletion (Aitken and Krausz, 2001). The types of ROS-induced DNA damage in spermatozoa in the experimental systems included modification of all bases and the production of base-free sites, deletions, frameshifts, ssDNA breaks, DNA protein crosslinks and chromosomal rearrangements (Halliwell and Aruoma, 1991) in both mitochondria and nuclear DNA. However, apoptosis was characterized by a dsDNA break (Allen et al., 1997), but not a ssDNA break.

Antioxidants, such as epididymal secretory GPx, superoxide dismutase and seminal plasma contents in the reproductive tract, play an important role in oxidative stress (Perry et al., 1993; Vernet et al., 1996; Twigg et al., 1998; van Overveld et al., 2000). Previous observations of a higher embryonic wastage and reduced fertility in terms of a decrease in implantation rate and an increase in postimplantation loss of embryos after removal of all or some male accessory sex glands in the golden hamster $(\mathrm{O}$ et al., 1988), structural abnormalities in implanted embryos (Jiang et al., 2001) and delay in sperm chromatin decondensation and DNA replication in the first cell cycle (Ying et al., 1998, 1999a) could be attributed to damage to DNA of spermatozoa in the absence of contact with secretions from paternal accessory sex glands. The results of the present study show that compared with the control hamsters, more spermatozoa from the TX group experienced ssDNA and dsDNA damage, but the extent of damage was higher only in the ssDNA type. However, removal of ampullary glands and the ventral prostate gland does not appear to have any effect, indicating that elements with a potential to protect spermatozoa from oxidative damage may originate from the dorsolateral prostate glands, coagulating glands or seminal vesicles. Moreover, a significantly higher dose-dependent response in incidence and extent of ssDNA damage was found in uterine spermatozoa ejaculated from hamsters with all male accessory sex glands removed (TX group) when incubated with NADPH compared with the control hamsters (SH group). However, this dose-dependent response was not observed in uterine spermatozoa ejaculated from hamsters with either ampullary glands or ventral prostate removed. These results further indicate that the ventral prostate gland and ampullary glands do not afford any protection to spermatozoa against $\mathrm{NADPH}$-induced DNA damage.

Oxidative stress has an influence on sperm motility, capacitation and fusion with the oocyte (Aitken et al., 1989, 1993). The present study demonstrated that NADPH induces a comparable dose-dependent decrease in spermoocyte fusion in spermatozoa from both TX and $\mathrm{SH}$ groups. This finding is in agreement with previous findings in which a lack of effect of deletion of male accessory sex glands on the fertilizing ability of spermatozoa in vivo and in vitro was reported (O et al., 1988; Ying et al., 1999b). However, the negative linear correlation between induced ssDNA damage and sperm-oocyte fusion rate in the TX group does indicate that ssDNA damage can reduce the ability of the spermatozoa to fuse with the oocytes (Morris et al., 2002). Whether this is a direct effect of NADPH remains to be established.

The results of the present study also show that uterine spermatozoa ejaculated by hamsters with all male accessory sex glands removed are more vulnerable to NADPH treatment in comparison with cauda epididymal spermatozoa. This difference might be related to uterine factors that are harmful to spermatozoa, such as nitric oxide (Norman and Cameron, 1996); amino acids (Fahning et al., 1967), which have been reported to stimulate production of $\mathrm{H}_{2} \mathrm{O}_{2}$ in bovine spermatozoa through the action of an amino acid oxidase (Lapointe and Sirard, 1998); leucocytes, mainly eosinophils (Perez et al., 1996), could also produce large quantities of $\mathrm{H}_{2} \mathrm{O}_{2}$ upon stimulation by seminal plasma (Hansen et al., 1987) and other ROS that were toxic to spermatozoa (Thompson et al., 1992; Williams et al.,1993). In addition, oestrogen has pro-oxidant and antioxidant effects. At oestrus, under the influence of oestrogen, endometrial epithelial NADPH oxidase produces NADPH (Moulton and Barker, 1971; Hilf et al., 1972; Swanson and Barker, 1983), superoxide anions (Laloraya et al., 1991; Jain et al., 1999, 2000) and hydrogen peroxide (Riley and Behrman, 1991). Optimal amounts of these oxidants were balanced for sperm capacitation by the oestrogenstimulated antioxidant system, which mainly included superoxide dismutase, peroxidase containing eosinophilic peroxidase and endogenous peroxidase associated with epithelial cells (Hosoya and Saito, 1981; Anderson et al., 1986; Riley and Behrman, 1991), and glutathione peroxidase (GPx)/reductase (GR) system (Ohwada et al., 1996; Diaz-Flores et al., 1999; Kaneko et al., 2001). It has been reported that in the hamster, hydrogen peroxide is needed to control oxidation of sperm membrane thiol groups during capacitation (Bize et al., 1991). It has been suggested that the combined effects of these uterine factors render the spermatozoa more vulnerable to NADPH treatment.

The present study demonstrated that spermatozoa incubated with NADPH and untreated spermatozoa showed the same incidence and extent of ssDNA. This finding indicates that our experimental procedure does not induce additional ssDNA damage, that the dose-dependent increase in both the incidence and extent of ssDNA damage after incubation with NADPH is indeed a bona fide induction by NADPH treatment (Aitken et al., 1997). The presence of NADPH oxidase in the sperm membrane was challenged by Richer and Ford (2001); they were not able to detect NADPH oxidase in the sperm membrane. However, in the present study, the addition of $50 \mathrm{U}$ superoxide dismutase $\mathrm{ml}^{-1}$ into flushing and incubation media resulted in a significant reduction in ssDNA damage in the TX after NADPH incubation $(\mathrm{H}$. Chen, P. H. Chow, A. L. M. Cheung and W. S. O, 
unpublished). This finding indirectly confirms the presence of NADPH-oxidase in the sperm membrane, as ROS generated by it could be counteracted by superoxide dismutase in vitro. Furthermore, Vernet et al. (2001) proved by RT-PCR that, in rat epididymal spermatozoa, this proposed membrane-bound NADPH oxidase is indeed an NADPH oxidoreductase complex in the sperm plasma membrane and is quite distinct from a similar system in the leucocyte.

In summary, the present study demonstrated that mature epididymal spermatozoa are less susceptible to NADPHinduced oxidative damage. Male accessory sex gland secretions do afford protection to spermatozoa against natural and induced oxidative DNA damage. The protective factor(s) appears to come from the coagulating glands, dorsolateral prostate glands and seminal vesicles; the absence of ampullary glands and the ventral prostate gland has little affect on fertility in vivo. Thus, even though spermatozoa may suffer oxidative genomic damage, the embryos may have adequate mechanism to repair the damage to allow full development.

The authors thank J. S. K. Chan and B. Fu from Department of Statistics and Actuarial Science for their advice on statistical analysis. This project is supported by grants from RGC 10203218/ 03678/20200/324 and HKU 10202769/03678/20200/301.

\section{References}

Aitken RJ (1995) Free radicals, lipid peroxidation and sperm function Reproduction, Fertility and Development 7 659-668

Aitken RJ and Fisher H (1994) Reactive oxygen species generation and human spermatozoa: the balance of benefit and risk Bioessays 16 259-267

Aitken RJ and Krausz C (2001) Oxidative stress, DNA damage and the $Y$ chromosome Reproduction 122 497-506

Aitken RJ and Vernet $\mathbf{P}$ (1998) Maturation of redox regulatory mechanisms in the epididymis Journal of Reproduction and Fertility Supplement $\mathbf{5 3}$ 109-118

Aitken RJ, Clarkson JS and Fishel S (1989) Generation of reactive oxygen species, lipid peroxidation and human sperm function Biology of Reproduction 41 183-197

Aitken RJ, Buckingham D and Harkiss D (1993) Use of a xanthine oxidase free radical generating system to investigate the cytotoxic effects of reactive oxygen species on human spermatozoa Journal of Reproduction and Fertility $97441-450$

Aitken RJ, Fisher HM, Fulton N, Gomez E, Knox W, Lewis B and Irvine S (1997) Reactive oxygen species generation by human spermatozoa is induced by exogenous NADPH and inhibited by the flavoprotein inhibitors diphenylene iodonium and quinacrine Molecular Reproduction and Development 47 468-482

Allen RT, Hunter WJ, III and Agrawal DK (1997) Morphological and biochemical characterization and analysis of apoptosis Journal of Pharmacological and Toxicological Methods 37 215-228

Alvarez JG, Touchstone JC, Blasco L and Storey BT (1987) Spontaneous lipid peroxidation and production of hydrogen peroxide and superoxide in human spermatozoa: superoxide dismutase as major enzyme protectant against oxygen toxicity Journal of Andrology 8 338-348

Anderson WA, Gabriel BW, Nerurkar SG, Wyche JH, Yates PE and Hanker JS (1986) Peroxidases induced in rat uterus by estrogen administration. II. Cytochemical and biochemical heterogeneity Journal of Submicroscopic Cytology 18 683-690

Bianchi PG, Manicardi GC, Bizzaro D, Bianchi U and Sakkas D (1993) Effect of deoxyribonucleic acid protamination on fluorochrome staining and in situ nick-translation of murine and human mature spermatozoa Biology of Reproduction 49 1083-1088
Bize I, Santander G, Cabello P, Driscoll D and Sharpe C (1991) Hydrogen peroxide is involved in hamster sperm capacitation in vitro. Biology of Reproduction 44 398-403

Chan OC, Chow PH and O WS (2001) Total ablation of paternal accessory sex glands curtails developmental potential in preimplantation embryos in the golden hamster Anatomy and Embryology (Berlin) 204 117-122

Chow PH, Pang SF, Ng KW and Wong TM (1986) Fertility, fecundity, sex ratio and the accessory sex glands in male golden hamsters International Journal of Andrology 9 312-320

de Lamirande E and Gagnon C (1995a) Capacitation-associated production of superoxide anion by human spermatozoa Free Radical Biology and Medicine 18 487-495

de Lamirande E and Gagnon C (1995b) Impact of reactive oxygen species on spermatozoa: a balancing act between beneficial and detrimental effects Human Reproduction 10 Supplement 1 15-21

Diaz-Flores M, Baiza-Gutman LA, Pedron NN and Hicks JJ (1999) Uterine glutathione reductase activity: modulation by estrogens and progesterone Life Sciences 65 2481-2488

Fahning ML, Schultz RH and Graham EF (1967) The free amino acid content of uterine fluids and blood serum in the cow Journal of Reproduction and Fertility 13 229-236

Fisher HM and Aitken RJ (1997) Comparative analysis of the ability of precursor germ cells and epididymal spermatozoa to generate reactive oxygen metabolites The Journal of Experimental Zoology 277 390-400

Griveau JF, Dumont E, Renard P, Callegari JP and Le Lannou D (1995) Reactive oxygen species, lipid peroxidation and enzymatic defence systems in human spermatozoa Journal of Reproduction and Fertility $10317-26$

Halliwell B and Aruoma OI (1991) DNA damage by oxygen-derived species. Its mechanism and measurement in mammalian systems FEBS Letters 281 9-19

Hansen PJ, Hoggard MP and Rathwell AC (1987) Effects of stallion seminal plasma on hydrogen peroxide release by leukocytes exposed to spermatozoa and bacteria Journal of Reproductive Immunology 10 157-166

Hilf R, McDonald E, Sartini J, Rector WD and Richards AH (1972) Response of uterine glucose-6-phosphate dehydrogenase isoenzymes to estrogen Endocrinology 91 280-286

Hosoya T and Saito T (1981) Comparative studies on estrogen-dependent peroxidases contained in uterine microsomes and fluid of rats and pigs The Journal of Biochemistry (Tokyo) 89 203-215

Hughes CM, Lewis SE, McKelvey-Martin VJ and Thompson W (1996) A comparison of baseline and induced DNA damage in human spermatozoa from fertile and infertile men, using a modified comet assay Molecular Human Reproduction 2 613-619

Iwasaki A and Gagnon C (1992) Formation of reactive oxygen species in spermatozoa of infertile patients Fertility and Sterility $\mathbf{5 7} 409-416$

Jain S, Saxena D, Kumar PG, Koide SS and Laloraya M (1999) Effect of estradiol and selected antiestrogens on pro- and antioxidant pathways in mammalian uterus Contraception 60 111-118

Jain S, Saxena D, Kumar GP and Laloraya M (2000) NADPH dependent superoxide generation in the ovary and uterus of mice during estrous cycle and early pregnancy Life Sciences 66 1139-1146

Jiang HY, Lee KH, Schneider C, O WS, Tang PL and Chow PH (2001) The growth arrest specific gene (gas6) protein is expressed in abnormal embryos sired by male golden hamsters with accessory sex glands removed Anatomy and Embryology 203 343-355

Jones R and Mann T (1976) Lipid peroxides in spermatozoa formation, role of plasmalogen and physiological significance Proceedings of the Royal Society London Series B, Biological Sciences 193 317-333

Kaneko T, luchi Y, Kawachiya S, Fujii T, Saito H, Kurachi H and Fujii J (2001) Alteration of glutathione reductase expression in the female reproductive organs during the estrous cycle Biology of Reproduction 65 1410-1416

Kodama H, Yamaguchi R, Fukuda J, Kasai H and Tanaka T (1997) Increased oxidative deoxyribonucleic acid damage in the spermatozoa of infertile male patients Fertility and Sterility $\mathbf{6 8} 519-524$

Kosower NS, Katayose H and Yanagimachi R (1992) Thiol-disulfide status and acridine orange fluorescence of mammalian sperm nuclei Journal of Andrology 13 342-348 
Laloraya M, Kumar GP and Laloraya MM (1991) Changes in the superoxide radical and superoxide dismutase levels in the uterus of Rattus norvegicus during the estrous cycle and a possible role for superoxide radical in uterine oedema and cell proliferation at proestrus Biochemistry and Cell Biology 69 313-316

Lapointe S and Sirard MA (1998) Catalase and oviductal fluid reverse the decreased motility of bovine sperm in culture medium containing specific amino acids Journal of Andrology 19 31-36

Lewis SE, McKinney KA and Thompson W (1994) Influence of pentoxifylline on human sperm motility in asthenozoospermic individuals using computer-assisted analysis Archives of Andrology 32 175-183

Morris ID, Ilott S and Brison DR (2002) The spectrum of DNA damage in human sperm assessed by single cell gel electrophoresis (Comet assay) and its relationship to fertilization and embryo development Human Reproduction 17 990-998

Moulton BC and Barker KL (1971) Synthesis and degradation of glucose-6phosphate dehydrogenase in the rat uterus Endocrinology 89 1131-1136

Norman JE and Cameron IT (1996) Nitric oxide in the human uterus Reviews of Reproduction 1 61-68

O WS, Chen HQ and Chow PH (1988) Effects of male accessory sex gland secretions on early embryonic development in the golden hamster Journal of Reproduction and Fertility 84 341-344

Ohwada M, Suzuki M, Sato I, Tsukamoto H and Watanabe K (1996) Glutathione peroxidase activity in endometrium: effects of sex hormones and cancer Gynecologic Oncology 60 277-282

Olive PL, Banath JP and Durand RE (1990) Heterogeneity in radiationinduced DNA damage and repair in tumor and normal cells measured using the "comet" assay Radiation Research 122 86-94

Ostling O and Johanson KJ (1984) Micro-electrophoretic study of radiationinduced DNA damages in individual mammalian cells Biochemical and Biophysical Research Communications 123 291-298

Palan P and Naz R (1996) Changes in various antioxidant levels in human seminal plasma related to immunoinfertility Archives of Andrology $\mathbf{3 6}$ 139-143

Perez MC, Furth EE, Matzumura PD and Lyttle CR (1996) Role of eosinophils in uterine responses to estrogen Biology of Reproduction $\mathbf{5 4} 249-254$

Perry AC, Jones R and Hall L (1993) Isolation and characterization of a rat cDNA clone encoding a secreted superoxide dismutase reveals the epididymis to be a major site of its expression The Biochemical Journal 293 (Part 1) 21-25

Richer SC and Ford WC (2001) A critical investigation of NADPH oxidase activity in human spermatozoa Molecular Human Reproduction 7 $237-244$

Riley JC and Behrman HR (1991) Oxygen radicals and reactive oxygen species in reproduction Proceedings of the Society for Experimental Biology and Medicine 198 781-791

Sakkas D, Mariethoz E, Manicardi G, Bizzaro D, Bianchi PG and Bianchi U (1999) Origin of DNA damage in ejaculated human spermatozoa Reviews of Reproduction 4 31-37

Sharma RK, Pasqualotto FF, Nelson DR, Thomas AJ, Jr and Agarwal A (1999) The reactive oxygen species-total antioxidant capacity score is a new measure of oxidative stress to predict male infertility Human Reproduction 14 2801-2807
Shen H and Ong C (2000) Detection of oxidative DNA damage in human sperm and its association with sperm function and male infertility Free Radical Biology and Medicine 28 529-536

Singh NP, McCoy MT, Tice RR and Schneider EL (1988) A simple technique for quantitation of low levels of DNA damage in individual cells Experimental Cell Research 175 184-191

Smith R, Vantman D, Ponce J, Escobar J and Lissi E (1996) Total antioxidant capacity of human seminal plasma Human Reproduction 11 1655-1660

Swanson LV and Barker KL (1983) Antagonistic effects of progesterone on estradiol-induced synthesis and degradation of uterine glucose-6phosphate dehydrogenase Endocrinology 112 459-465

Thompson LA, Barratt CL, Bolton AE and Cooke ID (1992) The leukocytic reaction of the human uterine cervix American Journal of Reproductive Immunology 28 85-89

Twigg J, Irvine DS, Houston P, Fulton N, Michael L and Aitken RJ (1998) latrogenic DNA damage induced in human spermatozoa during sperm preparation: protective significance of seminal plasma Molecular Human Reproduction 4 439-445

van Overveld FW, Haenen GR, Rhemrev J, Vermeiden JP and Bast A (2000) Tyrosine as important contributor to the antioxidant capacity of seminal plasma Chemico-Biological Interaction 127 151-161

Vernet P, Rigaudiere N, Ghyselinck N, Dufaure JP and Drevet JR (1996) In vitro expression of a mouse tissue specific glutathione-peroxidase-like protein lacking the selenocysteine can protect stably transfected mammalian cells against oxidative damage Biochemistry and Cell Biology 74 125-131

Vernet P, Fulton N, Wallace C and Aitken RJ (2001) Analysis of reactive oxygen species generating systems in rat epididymal spermatozoa Biology of Reproduction 65 1102-1113

Weissenberg R, Yossefi S, Oschry Y, Madgar I and Lewin LM (1994) Investigation of epididymal sperm maturation in the golden hamster International Journal of Andrology 17 256-261

Williams M, Thompson LA, Li TC, Mackenna A, Barratt CL and Cooke ID (1993) Uterine flushing: a method to recover spermatozoa and leukocytes Human Reproduction 8 925-928

Ying Y, Cheung MP, Chow PH and O WS (1999a) Effects of male accessory sex glands on sperm decondensation and oocyte activation during in vivo fertilization in golden hamsters International Journal of Andrology 22 68-76

Ying Y, Chow PH, Cheung MP and O WS (1999b) Male accessory sex gland secretions affect oocyte $\mathrm{Ca}^{2+}$ oscillations during in vitro fertilization in golden hamsters Molecular Human Reproduction 5 527-533

Ying Y, Chow PH and O WS (1998) Effects of male accessory sex glands on deoxyribonucleic acid synthesis in the first cell cycle of golden hamster embryos Biology of Reproduction 58 659-663

Received 26 April 2002.

First decision 20 June 2002.

Revised manuscript received 10 July 2002.

Accepted 12 July 2002. 